American Journal of Agricultural and Biological Sciences 4 (3): 192-200, 2009

ISSN 1557-4989

(C) 2009 Science Publications

\title{
Concentration and Physicochemical Properties of Chitosan Derivatives Determine the Induction of Defense Responses in Roots and Leaves of Tobacco (Nicotiana tabacum) Plants
}

\author{
${ }^{2}$ Alejandro B. Falcón-Rodríguez, ${ }^{3} J u a n$ C. Cabrera, \\ ${ }^{4}$ Eduardo Ortega and ${ }^{1}$ Miguel Ángel Martínez-Téllez \\ ${ }^{1}$ Centro de Investigación en Alimentación y Desarrollo, A. C. (CIAD), \\ Coordinación de Tecnología de Alimentos de Origen Vegetal (CTAOV), \\ Carretera a la Victoria Km. 0.6, A. P. 1735, Hermosillo 83000, Sonora, México \\ ${ }^{2}$ Laboratorio de Oligosacarinas, Departamento de Fisiología y Bioquímica Vegetal, \\ Instituto Nacional de Ciencias Agrícolas (INCA), Carretera a Tapaste, \\ Km. 31ㄹ, San José de las Lajas, La Habana 32700, Cuba \\ ${ }^{3}$ Unité de Recherche en Biologie Cellulaire Végétale, \\ Facultés Universitaires Notre-Dame de la Paix, Namur, Belgium \\ ${ }^{4}$ Laboratorio de Fisiología Vegetal, Departamento de Biología Vegetal, \\ Facultad de Biología, Universidad de la Habana, Cuba
}

\begin{abstract}
Problem statement: The chitosan derivatives promote diverse defensive responses in plants, which are affected by chitosan chemical features and concentration. Glucanase (EC 3.2.1.6), Phenylalanine Ammonia-Lyase (PAL, EC 4.3.1.5) and peroxidase (POD, EC 1.11.1.6) are key enzymes in tobacco defense responses. Thus, the aim of this study was to know the behavior of their enzymatic activity in leaves and roots of whole tobacco plants, previously elicited with chitosan derivatives of different molecular weight and acetylating degree. Approach: 25 day-old tobacco plants were treated with three chitosan derivatives (CH- 63, CH-88 and OLG) of different chemical features. True leaves and roots were sampled after three, six, nine and 12 days post-treatment for further evaluation of the enzymatic activities. Results: Chitosan treatments increased the activity of all three studied enzymes depending on the concentration and chemical feature of the derivative. The highest enzymatic activities with polymers occurred at $1 \mathrm{~g} \mathrm{~L}^{-1}$ while the oligochitosan mixture achieved good enzymatic levels as compared to controls from $0.1 \mathrm{~g} \mathrm{~L}^{-1}$ onwards. The Degree of Acetylation (DA) affected PAL activity; a more acetylated polymer induced a higher activity than a less acetylated one. However, the low levels of acetylation favored POD activity. The systemic induction of enzymatic activities was detected in leaves of treated plants after root application. The effect of the acetylation degree was systemically transmitted to the leaves by POD, but not by PAL activity; so the transmission of the acetylating degree influence beyond the tissue directly elicited by chitosan polymer depended on each enzymatic response tested. Conclusion: This study proved that various chitosan derivatives induced and raised lasting $\beta$-1,3-glucanase, PAL and POD activities in tobacco leaves and roots as local or systemic responses, which could lead to the accumulation of secondary metabolites and formation of barriers that all together enhance plant resistance against pathogens.
\end{abstract}

Key words: Induced resistance, PR-proteins, systemic response, acetylating degree

\section{INTRODUCTION}

Plants respond to pathogen attack with a complex set of preformed structures and inducible reactions. The inducible reactions require the perception of primary signal molecules from plant and fungal cell wall released in the pathogenesis process and recognized by plant cell membranes. This recognition triggers a wide range of plant enzymatic and chemical arsenal that attacks and degrades pathogen cell wall, removing

Corresponding Author: Miguel Ángel Martínez-Téllez, Centro de Investigación en Alimentación y Desarrollo, AC., Coordinación de Tecnología de Alimentos de Origen Vegetal, Carretera a la Victoria Km. 0.6, A. P. 1735, Hermosillo 83000, Sonora, México Fax: +52(662) 280-04-22 
oligosaccharides from this structure. The recognition of these exogenous oligosaccharides by the plant is known to amplify defensive signals as well as the number and magnitude of its responses against the pathogen ${ }^{[1,2]}$.

As inducible defensive responses, tobacco plants activate a great number of defense proteins including PR proteins ${ }^{[3]}$ and intermediate enzymes of metabolic pathways that generate compounds of the secondary metabolism and biochemical barriers for pathogen contention $^{[4]}$, as well as the synthesis of secondary signals for defense amplification ${ }^{[4,5]}$. Direct and indirect evidences proving the role of $\beta$-1,3-glucanase enzymes in protecting tobacco plants against pathogens have been reported as a result of their activation by infection or the increased resistance in these plants by constitutive $\beta$-1,3-glucanase gene expression ${ }^{[3,6,7]}$. Similarly, the importance of Phenylalanine AmmonioLyase (PAL) and Peroxidase (POD) enzymes for the synthesis of structures and secondary defensive signals in tobacco have also been reported ${ }^{[4,8,9]}$.

In plant tissues, extra cellular chitinases ${ }^{[10]}$ and possibly chitosanases ${ }^{[11]}$ in concert with $\beta$ 1-3 glucanase $^{[12]}$ are likely to partially degrade fungal cell wall polysaccharides producing chitin and chitosan diffusible fragments that may indicate the presence of a potential pathogen to plant tissue. Chitosan is the main derivative obtained from a natural polymer known as chitin by partial or total deacetylation of its amino groups. It is a polymer formed by $\beta$ 1-4 linked glucosamine residues that could be partially $\mathrm{N}$ acetylated $^{[13]}$.

Chitosan causes biological effects as plant growth promotion, the direct growth inhibition of several microorganisms, mainly fungi and elicits induced resistance in plants against their pathogen ${ }^{[14]}$. It has been reported that both, the inhibition of microbial growth and induction of some defensive responses in the plant, are affected by chitosan chemical features such as acetylating degree and molecular weight ${ }^{[14-16]}$. However, most of the previous reports, indicating the influence of the mentioned chemical features were performed in cell suspensions or in isolated plant organs, never in whole plants. In addition, chitosan concentration differentially affects plant defense induction and protection against pathogens, depending on plant specie, type of defense and the part of the plant that perceive the chitosan derivative ${ }^{[14,16-18]}$.

In advance, the behavior of LOX activity was reported in tobacco cell suspensions previously sensitized with jasmonates and later on elicited with $\operatorname{chitosan}^{[19]}$. Recently, it has been found that the chemical features of those chitosan derivatives sprayed to the plant could influence the activation of some defensive responses in whole plants of tobacco ${ }^{[20]}$. According to the above-mentioned, the aim of this study was to know the behavior of defensive enzymes activated in leaves and roots of whole tobacco plants, previously elicited with chitosan derivatives of different molecular weight and acetylating degree.

\section{MATERIALS AND METHODS}

Chemicals: To perform biological assays, three chitosan derivatives (CH-63, CH-88 and OLG) of different chemical features were used. $\mathrm{CH}-63$ and $\mathrm{CH}-$ 88 were two chitosan polymers of similar molecular weight and different acetylation degree (Table 1) obtained by the basic desacetylation of Cuban lobster chitin $^{[21]}$, while OLG was a mixture of chitosan oligosaccharides with a Degree of Polymerization (DP) ranging from 5-9, obtained by enzymatic hydrolysis from the $\mathrm{CH}-88$ polymer ${ }^{[16]}$.

Plant material: Two experiments were performed using tobacco (Nicotiana tabacum L.) plants from the Cuban variety "Corojo" cultivated in a substrate mixture (Pro-Mix, Canada), containing Peat $75-85 \%$ (Sphagnum canadiense), Vermiculite, Perlite, moisture agent and dolomitic and calcitic limestone for $\mathrm{pH}$ adjustment, under semi-controlled conditions with a light/dark and a temperature regime of $16 / 8 \mathrm{~h}$ and $28 / 24^{\circ} \mathrm{C}$, respectively.

Plant treatments with chitosan derivatives: In the first experiment, tobacco plants were grown for 25 days before being gently removed from the substrate, rinsed with distilled water and placed through the roots in eppendorf tubes (one plant per tube) containing $1 \mathrm{~mL}$ of the chitosan derivative solutions $(\mathrm{CH}-63, \mathrm{CH}-88$ and OLG) dissolved at $0.1,1$ and $2.5 \mathrm{~g} \mathrm{~L}^{-1}$ in potassium acetate $\mathrm{pH} 5.5,0.01 \%$ Tween 80 . As control, Tween 80/potassium acetate solution was used. Plants were incubated for $1 \mathrm{~h}$ and then changed to Hoagland solutions diluted 50 times and again incubated for $72 \mathrm{~h}$. Afterward, roots and true leaves were extracted.

\begin{tabular}{|c|c|c|c|}
\hline Derivative & Nomenclature & $\mathrm{DP}^{\mathrm{a}}$ & $\mathrm{DA}^{\mathrm{b}}$ \\
\hline Polymer & CH-63 & 794 & 36.5 \\
\hline Polymer & $\mathrm{CH}-88$ & 813 & 12 \\
\hline Oligochitosan & OLG & $5-9$ & $0-1^{\mathrm{c}}$ \\
\hline \multicolumn{4}{|c|}{$\begin{array}{l}\text { a: Average degree of polymerization determined by viscosimetry; } \\
\text { Degree of acetylation by potentiometry; }{ }^{c} \text { : Degree of acetylation by } \\
\text { MALDI-TOF }{ }^{[16]} \text {. Every oligosaccharide in the mixture coexists in two } \\
\text { forms: A non-N acetylated one and the other with only one } \\
\text { glucosamine N-acetylated }\end{array}$} \\
\hline
\end{tabular}


In the second experiment, 25 day-old tobacco plants were sprayed with two chitosan derivatives $(\mathrm{CH}-88$ and OLG) dissolved at $1 \mathrm{~g} \mathrm{~L}^{-1}$ in the former potassium acetate solution (also used as control). Plants were kept in the substrate for 3, 6, 9 and 12 days, respectively, before extracting true leaves.

Plant protein extraction: According to each experiment, true leaves and roots from plants, treated as stated before, were collected and ground in a porcelain mortar and pestle in liquid nitrogen. Powdered tissue was extracted in $50 \mathrm{mM}$ sodium acetate buffer $\mathrm{pH} 5.2$ containing $5 \mathrm{mM}$ EDTA, $14 \mathrm{mM} \beta$-mercapto-ethanol and $1.0 \mathrm{M} \mathrm{NaCl}$ at the rate of $1 \mathrm{~g}$ per $2 \mathrm{~mL}$ of buffer for leaves and $1 \mathrm{~g}$ per $1 \mathrm{~mL}$ for roots. The extract was then centrifuged at $12000 \mathrm{~g}$ for $15 \mathrm{~min}$ at $4^{\circ} \mathrm{C}$. The supernatant was collected in eppendorf tubes and stored at $-60^{\circ} \mathrm{C}$ for subsequent analysis.

Plant enzyme and protein determinations: Enzymatic activities were determined on supernatant of root and leaf extracts. $\beta$-1,3-glucanase activity was determined using laminarine (Sigma, USA) as substrate and according to the methodology of Boudart et al. ${ }^{[22]}$. In the assay, reducing sugars released from laminarine were quantified following Somogyi method ${ }^{[23]}$ and results were expressed as $\mu \mathrm{g}$ of glucose released per min per $\mathrm{mg}$ of protein $\left(\mu \mathrm{g} \mathrm{min}^{-1} \mathrm{mg}^{-1}\right)$. PAL and POD activity was determined using L-Phenyl-alanine and Guaiacol (Sigma, USA) as substrate, respectively, following the methodologies described by ${ }^{[15]}$. Enzymatic results of PAL were expressed as nm of transcinnamic acid formed per min per $\mathrm{mg}$ of protein $\left(\mathrm{nm} \mathrm{min}^{-1} \mathrm{mg}^{-1}\right)$. Enzymatic results of POD were expressed as Units of Enzymatic Activity (UEA) per min per $\mathrm{mg}$ of protein (UAE $\mathrm{min}^{-1} \mathrm{mg}^{-1}$ ) and one unit was defined as the amount of enzyme causing an increment of 0.1 absorbance units per min per $\mathrm{mg}$ of protein. Protein determinations were performed following a micro Lowry assay ${ }^{[24]}$ and expressed as mg of protein per fresh weight of plant tissue. Three determinations were performed per treatment and experiments were repeated twice. Data were analyzed through a simple ANOVA, using the statistical program Statgraphics plus 5.0 for Windows@ $\bigcirc$. Means with the same letters did not differ for $\mathrm{p}<0.05$ in the test of Tukey.

\section{RESULTS}

Defensive enzymes induced in roots and leaves of tobacco plants treated by chitosan derivatives of different molecular weight and acetylating degree.

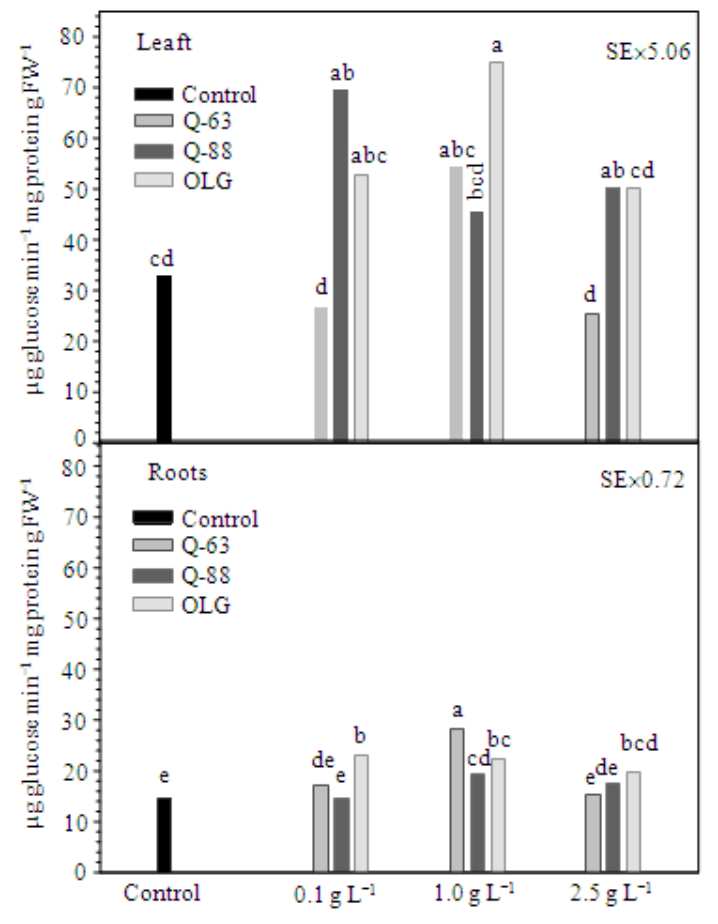

Fig. 1: $\beta$-1,3-glucanase enzymatic induction in leaves and roots of tobacco plants after applying through the roots with chitosan derivatives of different degree of acetylation and molecular weight. Enzymatic activity was determined on plant extracts after 3 days of treatments with Control, CH-63, CH-88 and OLG. Data are mean \pm SE of triplicate samples from one representative of two independent experiments

$\beta-1,3$-glucanase activity was activated in roots and leaves from tobacco plantlets by all three chitosan derivatives as shown in Fig. 1. Statistical differences between treatments and the control were more remarkable in plantlet roots than in its leaves. In roots, a higher and statistically different enzymatic activity from the control was recorded with the two polymers only at $1 \mathrm{~g} \mathrm{~L}^{-1}$ while the oligochitosan mixture induced $\beta$-1,3-glucanase activity surpassing the control with the three concentrations tested. In leaves, the less acetylated polymer $\left(0.1 \mathrm{~g} \mathrm{~L}^{-1}\right)$ and oligochitosan mixture $\left(1 \mathrm{~g} \mathrm{~L}^{-1}\right)$ induced a greater and different $\beta-1,3$ glucanase activity than the control.

Enzymatic response of PAL, followed a different behavior from $\beta$-1,3-glucanase activity, concerning the magnitude of its response, especially in roots. Again, differences between induced treatments and the control were more remarkable in roots than in leaves (Fig. 2). Higher and statistically different enzymatic increments 
from the control were recorded with the three concentrations of the more acetylated polymer (Q-63) and oligosaccharide mixture. No enzymatic activity different from control was obtained with any of the tested concentrations from the less acetylated polymer, which proves an effect of the acetylating degree in favor of more activity increments with the more acetylated polymer in roots (Fig. 2).

In turn, POD activity was more affected by the concentration of derivatives in both organs (Fig. 3). Both polymers induced the highest activity at $1 \mathrm{~g} \mathrm{~L}^{-1}$ concentration whereas the enzymatic activity induced by oligochitosan mixture fell down as the concentration increased. Less acetylated polymer activated the enzyme above the control with all the three concentrations tested; recording a more remarkable difference over the control in leaves (Fig. 3).

Time-course induction of defensive enzymes in tobacco leaves sprayed with chitosan derivatives of different molecular weight.

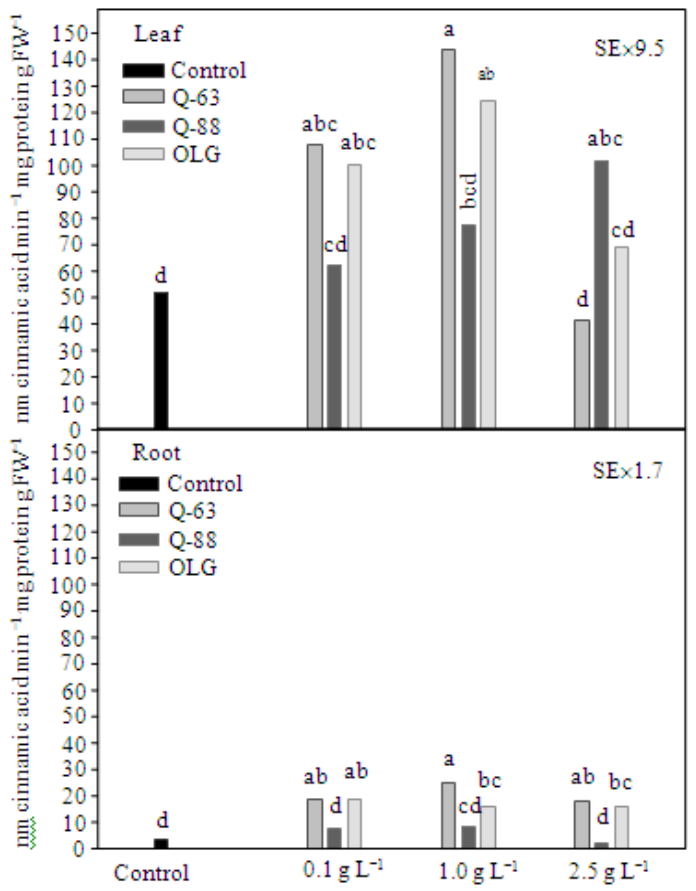

Fig. 2: PAL enzymatic induction in leaves and roots of tobacco plants after applying through the roots with chitosan derivatives of different degree of acetylation and molecular weight. Enzymatic activity was determined on plant extracts after 3 days of treatments with Control, $\mathrm{CH}-63, \mathrm{CH}-$ 88 and OLG. Data are mean \pm SE of triplicate samples from one representative of two independent experiments
Leaves of tobacco plants sprayed with $1 \mathrm{~g} \mathrm{~L}^{-1}$ of both chitosan derivatives of different molecular weight induced the three enzymatic activities in a long-lasting form (Fig. 4). Generally, activity increments due to chitosan treatments were higher and statistically different from the control activity levels during all the experiment.

Chitosan polymer caused the highest $\beta-1,3-$ glucanase activity, twice the control level, at six, nine and 12 days after spraying treatments. The enzymatic activity was lower with the oligochitosan mixture than with the polymer, but without statistical differences at three, six and nine days from being sprayed, while it reduced its activity after 12 days of treatment (Fig. 4).

The behavior of PAL activity was quite similar to that of $\beta$-1,3-glucanase. The highest enzymatic activity corresponded to the polymer, with a sustained threefold increment over the control level, still at 12 days of the treatment. PAL activity induced by oligochitosans was statistically different from the control at three, six and nine days from plant treatments, but it was always lower than the activity induced by the chitosan polymer (Fig. 4).

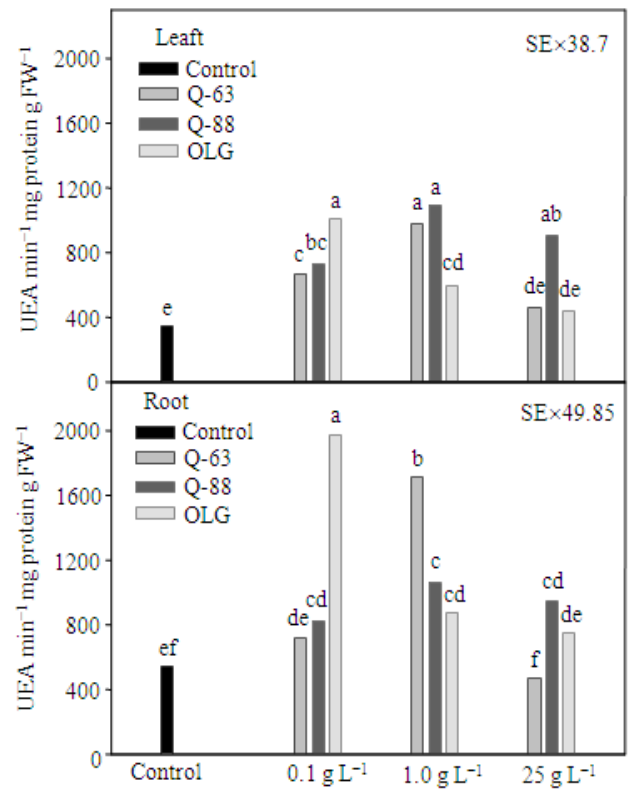

Fig. 3: POD enzymatic induction in leaves and roots of tobacco plants after applying through the roots with chitosan derivatives of different degree of acetylation and molecular weight. Enzymatic activity was determined on plant extracts after 3 days of treatments with Control, $\mathrm{CH}-63, \mathrm{CH}-$ 88 and OLG. Data are mean \pm SE of triplicate samples from one representative of two independent experiments 
Am. J. Agri. \& Biol. Sci., 4 (3): 192-200, 2009

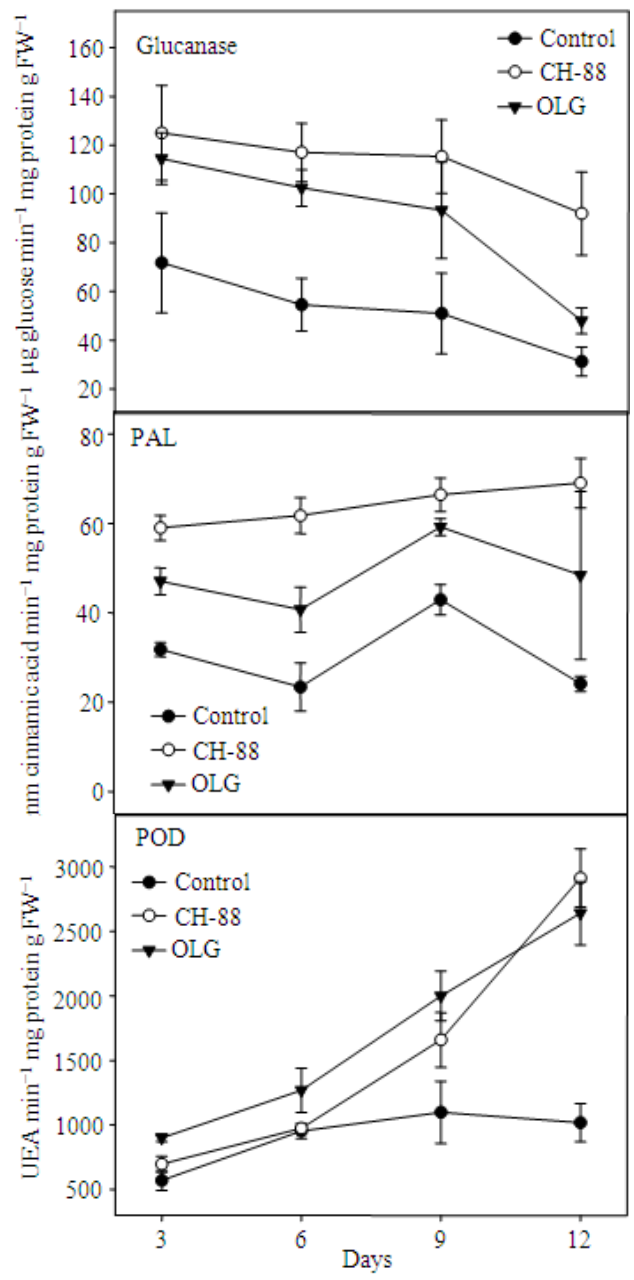

Fig. 4: Time-course of enzymatic induction in tobacco leaves after spraying with chitosan derivatives of different molecular weight. $\beta$-1,3-glucanase, PAL and POD were determined on leave extracts after 3, 6, 9 and 12 days of foliar application with polymeric (CH-88) and Oligomeric (OLG) chitosan at $1 \mathrm{~g} \mathrm{~L}^{-1}$. Data are mean \pm SE of triplicate samples from one representative of two independent experiments

The POD activity behavior was different from PAL and $\beta$-1,3-glucanase enzymes. The activity levels of both derivatives rose with time up to a maximum in both cases 12 days after spraying plants. The enzymatic activity induced by oligochitosans was higher and statistically different from the control and chitosan polymer after three and six days of treatments and only different from the control at six and nine days. The enzymatic activity was twice as much as the control for both derivatives 12 days after spraying plants (Fig. 4).

\section{DISCUSSION}

Several pathogen compounds have been shown to trigger defense mechanisms in plants ${ }^{[25,26]}$. When these compounds are applied to certain pathogen-susceptible plants, they can make them become resistant to that pathogen by means of inducing numerous histological and biochemical defensive responses ${ }^{[2]}$. Tobacco (Nicotiana tabacum L.) responds to pathogen attack with the temporal and stratified induction of an important number of defensive responses such as the well-known PR proteins ${ }^{[7,27,28]}$ and intermediate enzymes of metabolic routes involved in the synthesis of secondary defensive structures and the formation of chemical barriers that prevent the entry and multiplication of pathogens ${ }^{[4,8]}$.

Chitin and chitosan are essential components of fungal cell walls ${ }^{[29]}$ and their fragments are released by the action of plant defensive enzymes when both counterparts come into contact in the pathogenesis process $^{[26,30]}$. Chitosan has been involved to induce defensive responses and plant protection against many pathogens ${ }^{[14,18]}$. Regarding tobacco, the defensive response activation by chitosan, such as $\beta-1,3-$ glucanase, PAL and lipoxygenase, has been reported in cell suspensions and plant leaves ${ }^{[19]}$.

This study characterized the enzymatic response in leaves and roots of whole tobacco plants previously treated with chitosan derivatives of different acetylation degree and molecular weight. Results proved a differential induction of $\beta-1,3$-glucanase, PAL and POD activity according to the concentrations tested and chemical characteristics of the derivative used. According to these results, the highest differences between treatments and the control were recorded in leaves for $\beta$-1,3-glucanase and PAL activity, whereas these differences were also remarkable in leaves and roots for POD activity. Moreover, it demonstrates that the physiology of defensive activation in each plant organ can vary for every defensive response. Similarly, the absolute values of enzymatic activity in all treatments, including the control, were higher in leaves than in roots for $\beta-1,3$-glucanase and PAL activities, which could be due to that the leaf is a metabolically more active organ with a higher capacity of synthesis than the root, thus the expression of defense responses to elicitors in leaves might be higher. It is also important to take into account that the control was sprayed with potassium acetate (chitosan dissolvent), which can induce certain levels of plant defense responses with respect to its basal levels (data not shown), which can cause certain increments of PAL and POD activities in the control. 
The derivative concentration affected enzymatic activities depending on the type of chitosan tested. The best results for both polymers were observed at $1 \mathrm{~g} \mathrm{~L}^{-1}$ for PAL and POD activities; in fact, $\mathrm{CH}-63$ encouraged the highest activity for the three enzymes at the mentioned concentration. The enzymatic activity of oligochitosan mixture (OLG) is less dependent on the concentration, except for POD, where the highest activity occurred at the lowest concentration tested and decreased as concentration raised.

The effect of the chemical characteristics of chitosan on the enzymatic activity was not always observed, neither the effect recorded was similar for every enzyme. It seems there was an effect of the polymer acetylation degree on PAL activity in favor of more activity increments for higher acetylation degrees. This influence was only detected at root level; hence, maybe the effect of the Degree of Acetylation (DA) on PAL could only act on the directly elicited organ; however, it is not systemically transmitted to other plant organs. Conversely, POD activity was benefited by the less acetylated polymer, since the three concentrations in both organs induced enzymatic activity above the control. It seems that, in case of this enzyme, the effect of DA was systemically transmitted to leaves. Thus, the effect of chitosan acetylating degree could be locally or systemically induced, depending on each enzymatic response tested.

There are some previous reports in literature dealing with the effect of chitosan DA and MW on the induction of PAL and POD enzymatic activity; however, they were performed in cell suspensions ${ }^{[16]}$ or bioassays by injecting chitosan derivatives in plant leaves ${ }^{[15]}$. To our knowledge, the effect of both parameters was studied for the first time in the whole tobacco plants, with the possible influence of the organ coverts on the perception of chitosan features. Vander et al. ${ }^{[15]}$ demonstrated that the acetylation degree increments in chitosan polymer increased PAL and POD response levels. The results of this study are in agreement with the previous ones for PAL enzyme activation, but they are opposed to the results reported by these authors for the influence of DA on POD activation.

Nevertheless, the results of this study are in agreement with other recent ones explaining that oligochitosan mixtures with low DA caused a higher accumulation of $\mathrm{H}_{2} \mathrm{O}_{2}$ in suspension cells of Arabidopsis thaliana than similar mixtures with higher $\mathrm{DA}^{[16]}$. Taking into account that $\mathrm{H}_{2} \mathrm{O}_{2}$ increments or excessive accumulation are processed by peroxidase enzymes present in different cellular locations ${ }^{[31,32]}$, it can be expected a peroxidase activity increment when increasing $\mathrm{H}_{2} \mathrm{O}_{2}$ cell levels. On the other hand, literature shows different responses to chitosan DA for different defensive responses in plants. In this sense and contrary to the reported results that demonstrated PAL and POD activity increments as chitosan polymer DA increased $^{[15]}$, the synthesis and deposition of the defensive polymer, known as callose, showed more increments when plant suspension cells were elicited with lower acetylated chitosan polymers ${ }^{[33]}$.

The influence of chitosan DA and MW on plant defensive responses depends on its own biological system as well. Plant species play a role, especially when they belong to different groups, which could be the reason why Vander et al. ${ }^{[15]}$, who used to work with wheat plants (monocots), had different results regarding the influence of DA on the POD activity compared to ours and Cabrera et al. ${ }^{[16]}$ working with dicots.

In the second experiment, it was demonstrated that chitosan derivatives of different molecular weight can induce lasting defensive responses in tobacco leaves when plants are previously sprayed. These defensive responses can be activated in higher levels than the control for, at least, 12 days according to the results of each enzyme evaluated. Generally, results showed a remarkable activity difference for the three enzymes tested between the polymer and the oligochitosan mixture, favoring a higher activity with the polymer and having significant differences in the first six days concerning PAL and POD activities. As consequence, we conclude that the reduction of molecular weight of chitosan polymer until the values of degree of polymerization of the mixture tested reduced the levels of enzymatic activity induced, regarding the original polymer. Former authors speculated about the possibility that chitosan polymers and its fragments are not equally perceived in the plasmatic membrane of plants ${ }^{[26]}$. Meanwhile, possible protein candidates have been found for oligochitosan receptors, which seem that polymer interaction with membrane does not occur with a receptor itself but by means of interactions between chitosan polycationic groups and the negatively charged phospholipids of the membrane that, in turn, unchain membrane integrity changes ${ }^{[15,33]}$.

On the other hand, since OLG needs a lower concentration $\left(0,1 \mathrm{~g} \mathrm{~L}^{-1}\right)$ than the original polymer $(\mathrm{CH}-$ $88 ; 1 \mathrm{~g} \mathrm{~L}^{-1}$ ) to achieve high enzymatic levels (Fig. 1-3), it is possible to speculate that plant membranes perceive better chitosan fragments than polymeric ones, so maybe the higher (PAL) and lasting ( $\beta$-1,3-glucanase) activity found for chitosan polymer (CH-88) respect to OLG (Fig. 4) is a consequence from the differential chitosanolytic degradation of both elicitors by the enzymatic machinery of tobacco cells. Chitinolytic enzymes have been previously reported in the cellular apoplast of plants ${ }^{[10]}$. 
According to the time-course enzymatic responses (Fig. 4), $\beta$-1,3-glucanase and even PAL activities induced by the oligochitosan mixture (OLG) decreased almost to control levels about 12 days after spraying, whereas polymer activation kept the enzymatic level two times over the control. This difference could have a meaning in a long-lasting plant resistance and it could be caused by a faster degradation, through plant chitosanases, of the OLG elicitor with respect to chitosan polymer. In addition, the reduction of $\beta-1,3-$ glucanase and PAL activities at 12 days could be related to other defensive response increments, as for instance the very high POD activity recorded at 12 days. This idea could be supported by the fact that plants must do a balance in the energy cost to avoid the loss of precursors and energy from primary processes as growth and development. That is the reason why induced resistance is a temporal and inducible response in plants and could be regulated as the synthesis and degradation of chemical compounds. This subject is very interesting to search for chitosan derivatives since several papers reported the impact of induced resistance, by elicitor application, on plant growth and development ${ }^{[34]}$.

Because of the critical role in tobacco resistance of PAL, as a key enzyme in the phenylpropanoid pathway directed to precursors of metabolic and anatomic defenses ${ }^{[4,9]}$; POD, as a group of essential enzymes in the formation and metabolism of reactive oxygen species and intramolecular reticulation of phenols in plant cell wall ${ }^{[8,32]}$ and PR-proteins, as $\beta 1-3$ glucanase that hydrolyses the $\beta$ 1-3 glucan components of pathogen cell wall ${ }^{[12]}$ and it is associated to tobacco resistance against pathogens ${ }^{[7]}$; the activation of these three enzymes two to three times above the level of the control in a lasting way, presupposes the activation of induced resistance against pathogens and opens a question about the particular importance of each enzyme in tobacco protection against a specific pathogen. Recently, we demonstrated the activation of systemic resistance in this tobacco variety against $P$. nicotianae by chitosan derivatives ${ }^{[20]}$. In the near future, we are interested in investigating the relationship between tobacco resistance against $P$. nicotianae and the particular weight of every enzyme tested in the plant protection induced by chitosan derivatives.

In brief, this study proved that various chitosan derivatives induced and raised lasting $\beta-1,3$-glucanase, PAL and POD activities in tobacco leaves and roots as local or systemic responses, which could lead to the accumulation of secondary metabolites and formation of barriers that all together enhance plant resistance against pathogens. Besides the basic importance of differential activation of defensive enzymes with different chitosan derivatives, these results could also be worth for future practical protection of tobacco plants against pathogen attacks with chitosan derivatives.

\section{ACKNOWLEDGEMENT}

Thanks to CONACyT-Mexico and International Foundation for Sciences for its financial support (Project F-4446-1). This research is part of a $\mathrm{PhD}$ thesis of the first author performed at Instituto Nacional de Ciencias Agrícolas, Cuba and Centro de Investigación en Alimentación y Desarrollo, A. C., Mexico, in collaboration with Universitaires Notre-Dame de la Paix, Namur, Belgium, and Universidad de la Habana, Cuba. Thanks to Olivia Briceño and Socorro Vallejo for technical assistance and Emmanuel Aispuro for reviewing the manuscript.

\section{REFERENCES}

1. Esquerré-Tugayé, M.T., G. Boudart and B. Dumas, 2000. Cell wall degrading enzymes, inhibitory proteins and oligosaccharides participate in the molecular dialogue between plants and pathogen. Plant Physiol. Biochem., 38: 157-163. DOI: 10.1016/S0981-9428(00)00161-3

2. Klarzynski, O. and B. Fritig, 2001. Stimulation des défenses naturelles des plantes. C.R. Acad. Sci. Paris, Sciences de la vie/Life Sci., 324: 953-963. DOI: 10.1016/S0764-4469(01)01371-3

3. Leubner-Metzger, G. and F. Meins, 1999. Functions and Regulation of Plant $\beta-1,3-$ Glucanases (PR-2). In: Pathogenesis-Related Proteins in Plants, Datta, S.K. and S. Muthukrishnan (Eds.). CRC Press, Boca Raton, USA., ISBN: 0849306973, pp: 49-76.

4. Dixon, R.A., L. Achnine, P. Kota, C.J. Liu, M.S.S. Reddy and L. Wang, 2002. The phenylpropanoid pathway and plant defense-a genomics perspective. Mol. Plant Pathol., 3: 371-390. DOI: 10.1046/j.1364-3703.2002.00131.x

5. Dempsey, D.A., J. Shah and D.F. Klessig, 1999. Salicylic acid and disease resistance in plants. Crit. Rev. Plant Sci., 18: 547-575. http://cat.inist.fr/?aModele=afficheN\&cpsidt=1902148

6. Lusso, M. and J. Kuć, 1996. The effect of sense and antisense expression of the PR-N gene for $\beta$ 1,3-glucanase on disease resistance of tobacco to fungi and viruses. Physiol. Mol. Plant Pathol., 49: 267-283.

http://cat.inist.fr $/$ ?aModele $=$ afficheN\&cpsidt $=2596$ 974 
7. Funnell, D.L., C.B. Lawrence, J.F. Pedersen and C.L. Schardl, 2004. Expression of the tobacco $\beta$ 1,3-glucanase glucanase gene, PR-2d, following induction of SAR with Peronospora tabacina. Physiol. Mol. Plant Pathol., 65: 285-296. DOI: 10.1016/j.pmpp.2005.02.010

8. Ye, X.S., S.Q. Pan and J. Kuć, 1990. Association of pathogenesis-related proteins and activity of peroxidases, $\beta$-1,3-glucanase and chitinase with systemic induced resistance to blue mould of tobacco but not to systemic tobacco mosaic virus. Physiol. Mol. Plant Pathol., 36: 523-531. http://cat.inist.fr/?aModele $=$ afficheN\&cpsidt $=1927$ 3059

9. Blount, J.W., K.L. Korth, S.A. Masoud, S. Rasmussen, C. Lamb and R.A. Dixon, 2000. Altering expression of cinnamic acid 4-hydroxylase in transgenic plants provides evidence for a feedback loop at the entry point into the phenylpropanoid pathway. Plant Physiol., 122: 107-116. http://www.plantphysiol.org/cgi/reprint/122/1/107

10. Collinge, D.B., K.M. Kragh, J.D. Mikkelsen, K.K. Nielsen, U. Rasmussen and K. Vad, 1993. Plant chitinases. Plant J., 3: 31-40. DOI: 10.1111/j.1365-313X.1993.tb00008.X

11. Grenier, J. and A. Asselin, 1990. Some pathogenesis-related proteins are chitosanases with lytic activity against fungal spores. Mol. PlantMicrobe Interact., 3: 401-407. http://cat.inist.fr/?aModele=afficheN\&cpsidt=19355674

12. Mauch, F., B. Mauch-Mani and T. Boller, 1988. Antifungal hydrolases in pea tissue. II. Inhibition of fungal growth by combinations of chitinase and $\beta$ 1-3 glucanase. Plant Physiol., 88: 936-942. http://cat.inist.fr/?aModele $=$ afficheN\&cpsidt $=7371238$

13. Majeti, N.V. and R. Kumar, 2000. A review of chitin and chitosan applications. React. Funct. Polym., 46: 1-27. http://cat.inist.fr/?aModele $=$ afficheN\&cpsidt $=8033$ 21

14. Bautista-Baños, S., A.N. Hernández-Lauzardo, M.G. Velázquez-del Valle, M. Hernández-López, E. Ait Barka, E. Bosquez-Molina and C.L. Wilson, 2006. Chitosan as a potential natural compound to control pre and postharvest diseases of horticultural commodities. Crop Protect., 25: 108-118. DOI: 10.1016/j.cropro.2005.03.010

15. Vander, P., K.M. Varum, A. Domard, N.E. El Gueddari and B.M. Moerschbacher, 1998. Comparison of the ability of partially $\mathrm{N}$-acetylated chitosans and chitooligosaccharides to elicit resistance reactions in wheat leaves. Plant Physiol., 118: 1353-1359. http://www.plantphysiol.org/cgi/reprint/118/4/1353
16. Cabrera, J.C., J. Messiaen, P. Cambier and P. Van Cutsem, 2006. Size, acetylation and concentration of chitooligosaccharide elicitors determine the switch from defense involving PAL activation to cell death and water peroxide production in Arabidopsis cell suspensions. Physiol Plantarum, 127: 44-46. DOI: 10.1111/j.13993054.2006.00677.x

17. Sharathchandra, R.G., S. Niranjan Raj, N.P. Shetty, K.N. Amruthesh and H.S. Shetty, 2004. A Chitosan formulation Elexa $^{\mathrm{TM}}$ induces downy mildew disease resistance and growth promotion in pearl millet. Crop Prot., 23: 881-888. DOI: 10.1016/j.cropro.2003.12.008

18. Trotel-Aziz, P., M. Couderchet, G. Vernet and A. Aziz, 2006. Chitosan stimulates defense reactions in grapevine leaves and inhibits development of Botrytis cinerea. Eur. J. Plant Pathol., 114: 405-413. http://cat.inist.fr/?aModele $=$ afficheN\&cpsidt $=17896803$

19. Dubery, I.A., L.G. Teodorczuk and A.E. Louw, 2000. Early responses in methyl jasmonatepreconditioned cells toward pathogen-derived elicitors. Mol. Cell Biol. Res. Commun., 3: 105-110. DOI: $10.1006 / \mathrm{mcbr} .2000 .0198$

20. Falcón, A.B., J.C. Cabrera, D. Costales, M.A. Ramírez, G. Cabrera, V. Toledo and M.A. Martínez-Téllez, 2008. The effect of size and acetylation degree of chitosan derivatives on tobacco plant protection against Phytophthora parasitica nicotianae. World J. Microbiol. Biotech., 24: 103-112. DOI: 10.1007/s11274-007-9445-0

21. Methacanon, P., M. Prasitsilp, T. Pothsree and J. Pattaraarchachai, 2003. Heterogeneous Ndeacetylation of squid chitin in alkaline solution. Carbohydr. Polym., 52: 119-123. DOI: 10.1016/S0144-8617(02)00300-4

22. Boudart, G., C. Lafitte, J.P. Barthe, D. Frasez and M.-T. Esquerré-Tugayé, 1998. Differential elicitation of defense responses by pectic fragments in bean seedlings. Planta, 206: 86-94. DOI: $10.1007 / \mathrm{s} 004250050377$

23. Somogyi, M., 1952. Notes on sugar determination. J. Biol. Chem., 195: 19-23. http://www.ncbi.nlm.nih.gov/pubmed/14938350

24. Samuel S.M.S., 1994. Methods in plant molecular biology and agricultural biotechnology: A laboratory training manual. Asian Research and Development Center, Shanhua, Tainan, Taiwan (ROC), $\quad$ pp: 94. http://www.cababstractsplus.org/abstracts/Abstract. aspx?AcNo=19946798908

25. Ebel, J. and D. Scheel, 1997. Signals in HostParasite Interactions. In: The Mycota V, Part A. Plant Relationships, Carroll, G.C. and P. Tudzynski (Eds.). Springer-Verlag, Berlin Heidelberg, ISBN: 03540580069, pp: 85-105.

26. Shibuya, N. and E. Minami, 2001. Oligosaccharide signaling for defenses responses in plant. Physiol. Mol. Plant Pathol., 59: 223-233. DOI: 10.1006/pmpp.2001.0364 
27. Pan, S.Q., X.S. Ye and J. Kuć, 1991. Association of $\beta$-1,3-glucanase activity and isoform pattern with systemic resistance to blue mould in tobacco induced by stem injection with Peronospora tabacina or leaf inoculation with tobacco mosaic virus. Physiol. Mol. Plant Pathol., 39: 25-39. http://cat.inist.fr/?aModele $=$ afficheN\&cpsidt $=5454564$

28. van Loon, L.C., 1999. Occurrence and Properties of Pathogenesis-Related Proteins. In: Pathogenesis-Related Proteins in Plants, Datta, S.K. and S. Muthukrishnan (Eds.). CRC Press, USA., ISBN: 0849306973, pp: 1-19.

29. Wessels, J.G.H. and J.H. Sietsma, 1981. Fungal Cell Walls: A Survey. In: Plant Carbohydrates II, Tanner, W. and F.A. Loewus (Eds.). SpringerVerlag Berlin, Germany, ISBN: 0387110070, pp: 352-394.

30. Agrios, G.N., 1997. Plant Pathology. 4th Edn., Academic Press, New York, USA., ISBN: 0120445646, pp: 93.
31. Resende, M.L.V., A.M.L. Salgado and Z.M. Chaves, 2003. Espécies ativas de oxigênio na desposta de defesa de plantas a patógenos. Fitopatol. Bras., 28:123-130.DOI:10.1590/S0100-41582003000200001

32. Torres, M.A., J.D.G. Jones and J.L. Dangl, 2006. Reactive oxygen species signaling in response to pathogens. Plant Physiol., 141: 373-378. DOI: 10.1104/pp.106.079467

33. Kauss, H., W. Jeblick and A. Domard, 1989. The degree of polymerization and $\mathrm{N}$-acetylation of chitosan determine its ability to elicit callose formation in suspension cells and protoplasts of Catharanthus roseus. Planta, 178: 385-392. DOI: 10.1007/BF00391866

34. Heil, M. and R. Bostock, 2002. Induced Systemic Resistance (ISR) against pathogens in the context of induced plant defenses. Ann. Bot., 89: 503-512. DOI: $10.1093 / \mathrm{aob} / \mathrm{mcf076}$ 